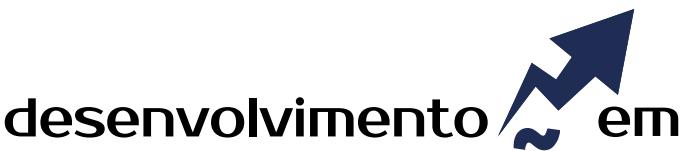 QUESTÃO
}

\section{Percepção Ambiental de Trabalhadores em Empresa Certificada ISO 14001: práticas e comportamentos}

http://dx.doi.org/10.21527/2237-6453.2018.45.316-335

Recebido em: $27 / 1 / 2017$

Aceito em: 18/4/2018

\section{Alexandre de Oliveira e Aguiar ${ }^{1}$, Cristiano Silveira Ribeiro ${ }^{2}$, Ana Paula Branco do Nascimento ${ }^{3}$}

\begin{abstract}
RESUMO
Empresas certificadas no Sistema de Gestão Ambiental ISO14001 desenvolvem programas para controle de seus aspectos ambientais por meio de procedimentos e práticas como coleta seletiva de resíduos, medidas de economia de energia e consumo de água, entre outros. A aplicação de práticas ambientais dentro da empresa pode influenciar a atitude ambiental do trabalhador fora dela. Este trabalho visa a estudar as práticas ambientais aplicadas pelo trabalhador no interior de uma empresa, a correlação desta com a vida cotidiana e se essas práticas estão relacionadas com a atitude do trabalhador fora do ambiente profissional. Foram obtidas 147 respostas de um questionário desenvolvido, especificamente para esta pesquisa, com funcionários de uma empresa de tratamento de superfície de metais. Os resultados foram tratados analisando-se as correlações bivariadas entre as respostas. Além do questionário, foram obtidas informações operacionais e de gestão ambiental da empresa. A análise dos resultados triangulou ambas informações. Destaca-se que entre as assertivas ligadas à postura da empresa, aquelas em que a atitude da liderança serve como estímulo ao comportamento ambientalmente responsável, se correlacionou com o maior número de assertivas sobre comportamento do funcionário. Como resultado da pesquisa realizada concluiu-se que as ações de formação de desenvolvimento dos trabalhadores podem ser revistas no sentido de apresentar abordagens práticas à vida profissional e cotidiana, de forma a despertar no trabalhador a percepção ambiental sobre a relação de seus impactos internos e externos sobre o meio ambiente.
\end{abstract}

Palavras-chave: Gestão ambiental. Treinamento ambiental. Percepção ambiental. Comportamento ambiental.

\section{WOKERS' ENVIRONMENTAL PERCEPTION IN AN ISO 14001 CERTIFIED COMPANY}

\section{ABSTRACT}

ISO 14001 Environmental Management Systems certified companies develop programs to control their environmental aspects by means of procedures and practices such as segregated waste collection, reduction of consumption of energy and water, among others. The implementation of environmental practices within the company can influence the environmental attitude of the worker in the outer side. This work aims to study the environmental practices applied by the worker within a company, its correlation with everyday life and whether these practices are related to the attitude of the worker outside the professional environment. A total of 147 responses were obtained for a questionnaire specifically developed for this research with employees of a metal surface treatment company. The results were treated by analyzing the bivariate correlations between responses. In addition to the questionnaire, operational and environmental management information was obtained from the company. The analysis of the results triangulated both information. It should be emphasized that among the assertions linked to the company's stance those in which the leadership attitude serves as a stimulus to environmentally responsible behavior correlated with the greater number of assertions about employee behavior. As a result of the research carried out, it was concluded that the development training actions of workers can be revised in order to present practical approaches to professional and daily life and so as to awaken in the worker the environmental perception about the relation of their internal and external impacts on the environment.

Keywords: Environmental management. Environmental training. Environmental perception. Environmental behavior.

\footnotetext{
${ }^{1}$ Doutor em Saúde Pública pela Faculdade de Saúde Pública da USP. Professor da Universidade Nove de Julho. aaguiar@uni9.pro.br

${ }^{2}$ Mestre em Administração - Gestão Ambiental e Sustentabilidade pela Universidade Nove de Julho. Consultor do MWC Office. cristiano@ mwcoffice.com.br

${ }^{3}$ Doutora em Ecologia Aplicada pela Universidade de São Paulo. Professor da Universidade Nove de Julho. apbnasci@yahoo.com.br
} 
Sistemas de gestão ambiental, de acordo com a norma internacional ISO 14001 e sua certificação por terceira parte, é uma ferramenta comumente usada por empresas para enfrentar suas questões ambientais e demonstrar para os stakeholders uma atuação coerente com sua política ambiental. Conforme dados da International Organization for Standardization - ISO (2016), o número de unidades de negócio certificadas ISO 14001 é de quase 300.000 no mundo e aproximadamente 3.000 no Brasil. Esta norma internacional é um padrão normativo em que a organização deve estabelecer seus objetivos e metas com a finalidade de controlar seus aspectos ambientais e atender aos requisitos legais a ela aplicáveis, determinando, desta forma, medidas de controle e monitoramento ambiental a seus processos de trabalho e atividades.

Darnall (2006), em estudos realizados com empresas americanas, concluiu que a busca pela certificação ISO 14001 é motivada por fatores como política institucional, conformidade legal e necessidades em atender requisitos do cliente. As pressões do mercado, influenciadas pela possibilidade de aumento das receitas, alcançando a vantagem competitiva, melhora das relações públicas e melhora da imagem da organização, são outros fatores por ele apontados.

Conforme a Associação Brasileira de Normas Técnicas - ABNT (ASSOCIAÇÃO..., 2004), para atingir o desempenho esperado na ISO 14001, a organização que a aplica deve planejar e fornecer treinamentos. Isso tem a finalidade de desenvolver as competências nos trabalhadores e conscientizá-los em relação às práticas ambientais quanto aos aspectos e impactos significativos da organização, minimizando ou neutralizando, deste modo, tais impactos.

O que se espera com o desenvolvimento das competências ambientais nos trabalhadores é oferecer o conhecimento dos fatores de trabalho relacionados ao meio ambiente com relação aos aspectos e impactos ambientais, para que seja possível o desenvolvimento da prática aplicada à tarefa, desenvolvendo, consequentemente, a percepção e o comportamento do trabalhador para assuntos que dizem respeito ao meio ambiente. Conforme pesquisa realizada por Campos e Pol (2010), trabalhadores que atuam em empresas certificadas em Sistemas de Gestão ISO 14001 apresentam, em seus comportamentos fora da organização, características pró-ambientais. Desta forma, apesar de não ter como enfoque a mudança do comportamento do trabalhador fora dos limites da organização, as empresas apresentam uma parcela de contribuição neste sentido.

Diante dos fatores expostos, pergunta-se: As práticas ambientais aprendidas na empresa podem influenciar o comportamento do funcionário na sua vida cotidiana? 0 objetivo do trabalho foi estudar a potencial relação entre práticas ambientais dentro de uma empresa e o comportamento declarado dos funcionários em relação a essas práticas no seu cotidiano.

O artigo apresenta a fundamentação teórica, a metodologia da pesquisa, incluindo o desenvolvimento e aplicação do questionário, o tratamento estatístico dos dados e a discussão com base na literatura. 


\section{FUNDAMENTAÇÃO TEÓRICA}

\section{Sustentabilidade, Gestão Ambiental e seus Indicadores}

Conforme Valle (2012) e Pelicioni (2007), os temas sustentabilidade e meio ambiente têm sido discutidos e considerados em diversas ocasiões em nossa sociedade. 0 conceito de desenvolvimento sustentável foi introduzido por meio do documento Relatório de Brudtland, intitulado Nosso Futuro Comum (COMISSÃO..., 1987), como: "satisfazer as necessidades das pessoas sem comprometer as perspectivas das gerações futuras". Esse conceito apresentou paradigma de desenvolvimento, no qual as necessidades do presente são atendidas sem comprometer a capacidade das futuras gerações de atenderem suas próprias necessidades (camada de ozônio e controle de resíduos).

Nesse sentido, Sachs (1993) trabalha com o conceito de ecodesenvolvimento, contribuindo para abrir a utopia do desenvolvimento sustentável em dimensões conceituais que estabelecem o caminho para a ação em harmonia com o meio ambiente (OLIVEIRA; MONTEIRO, 2015). São elas a sustentabilidade social, econômica, ecológica, espacial e cultural. Entre as estratégias de ação, Sachs (1993) chama a atenção para a necessidade de mudança de estilos de vida, padrões de consumo e funções de produção. Ao aplicar o conceito ao mundo dos negócios e expressar a sustentabilidade, Elkington (1997) criou a figura do triple bottom line, um conjunto de três linhas de base horizontais que representa uma relação de sustentação, segundo a qual a linha ambiental dá sustentação à econômica por fornecer os recursos naturais, e a econômica dá sustentação à social por viabilizar meios de subsistência à população. Entre os ajustes necessários, são destacadas mudanças de valores no negócio e a valorização dos ciclos dos produtos e materiais.

Boff (2013) é um crítico desta visão, argumentando que o termo "desenvolvimento» acaba por ser enganoso e mesmo desnecessário, e o que importa é a «sociedade sustentável». De qualquer modo, converge com os outros autores ao ressaltar que a sociedade somente será sustentável se ela se concentrar nos recursos renováveis e usar o mínimo possível os não renováveis. De acordo com Boff (2013), vivemos numa sociedade do descuido generalizado, em que é demonstrado descasos com o planeta, com a vida, com as coisas públicas, entre outros. Cuidar está relacionado com algo além da atitude, ou seja, com preocupação, responsabilidade e envolvimento. Em outras palavras, o cuidado entra na natureza e na constituição do ser humano sendo as práticas sustentáveis ações importantes que buscam devolver o equilíbrio ao planeta. Neste contexto, Leff (2002) enfatiza a urgência da construção social do mundo atual, em que emerjam novos valores e racionalidades que orientem práticas e comportamentos.

Shrivastava (1995) e Hart (1997), sobre o tema sustentabilidade, destacaram a necessidade de as empresas assumirem o compromisso sustentável, considerando o efeito em seu negócio, nas atividades e nos produtos, sobre os fatores ambientais, econômicos e sociais. O rápido crescimento da economia apresenta necessidade de controle do uso dos recursos naturais e preocupação com as futuras gerações. 
Para Shrivastava (1995), a mudança necessária ocorreria com a aplicação de um modelo de gestão que considere os conceitos organizacionais, objetivos, estratégias, estrutura, desempenho e as necessidades ambientais relacionadas aos principais impactos causados pela empresa ao meio ambiente.

Conforme Sarkis (1998), a aplicação de modelos sistêmicos pode auxiliar no desenvolvimento e na evolução do negócio sobre os conceitos que permeiam o meio ambiente. Como um dos modelos, apresentou os requisitos do Sistema de Gestão Ambiental, existente na família de normas ISO 14000.

\section{ISO 14001 e as Práticas Ambientais}

Em busca de manter uma relação responsável com o meio ambiente, como contribuição à sustentabilidade, e para demonstrar esse compromisso, uma das alternativas disponíveis para as empresas é a introdução de sistemas de gestão ambiental de acordo com a norma ISO 14001. Ribeiro Neto, Tavares e Hoffman (2008) ressaltaram que a ISO 14001 apresenta requisitos relativos a um sistema de gestão ambiental e permite a uma organização desenvolver e instituir uma política de meio ambiente de forma a atingir os objetivos ambientais, atender todos os requisitos legais aplicáveis e controlar os impactos ambientais significativos existentes em seus processos de trabalho.

A Norma ISO 14001 (ASSOCIAÇÃO..., 2004) está baseada na metodologia PDCA, abreviatura das palavras em inglês Plan - Do - Check - Act, em português Planejar - Executar - Verificar - Agir, e representa um princípio de melhoria contínua apresentado em sua estrutura na forma de itens ou elementos contendo requisitos para aplicação, que vão do 4.2 ao 4.6. Cada qual aborda um diferente assunto: 4.2. Política Ambiental, 4.3. Planejamento, 4.4. Implementação e Operação, 4.5. Verificação e 4.6. Análise pela Administração.

Os itens da norma ISO 14001 (ASSOCIAÇÃO..., 2004) são representados na Figura 1 por meio de um espiral de melhoria contínua, apresentando estrutura PDCA por um modelo evolutivo. Considera o atendimento à política ambiental todas as etapas de aplicação, partindo da fase de planejamento, seguido pelas demais etapas até sua revisão em análise crítica, que serve de realimentação para um novo planejamento.

Figura 1 - Representação ISO 14001 e PDCA

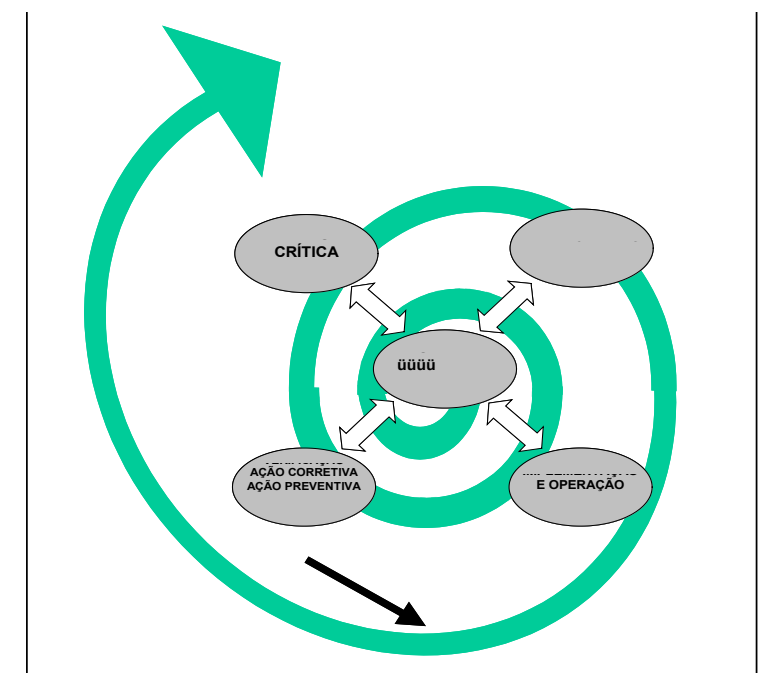

Fonte: AGUIAR, 2004. 
Dentre todos os requisitos da Norma ISO 14001 (ASSOCIAÇÃO..., 2004), o de número 4.3.3 apresentou os objetivos, metas e programas do Sistema de Gestão Ambiental. Para atendimento a este quesito a empresa deve elaborar programas ambientais com a finalidade de neutralizar ou controlar os aspectos e impactos ambientais significativos de seus processos de trabalho. Esses programas refletem em itens de Controle Operacional envolvendo procedimentos de trabalho e ações ambientais necessárias, como coleta seletiva, redução de consumo de recursos naturais, controle de poluição, entre outras aplicadas como prática cotidiana pelos trabalhadores dentro da empresa. A norma não é prescritiva quanto a práticas de gestão ambiental. Ela define "o que" deve ser feito (estrutura e requisitos), mas não "como" deve ser feito (tecnologias específicas, frequências, formas de organização do trabalho, etc.).

Ainda conforme a ISO 14001 (ASSOCIAÇÃO..., 2004), o desenvolvimento dos programas ocorre por meio da definição de responsabilidades a cada uma das partes envolvidas na sua aplicação. Para tanto, os envolvidos devem receber treinamento e orientação adequados para o exercício de suas atividades dentro do que se espera como resultado de desempenho do Sistema de Gestão Ambiental. Considera-se, desta forma, o comportamento do trabalhador como um importante fator para a empresa aplicar os programas ambientais e as ações planejadas, com a finalidade de atingir os objetivos por ela definidos.

Heras-Saizarbitoria e Boiral (2013) lembram que ainda há lacunas no conhecimento no campo de adoção de normas como ISO 9001 e ISO 14001 em diversos temas, entre eles os benefícios da adoção das normas, incluindo a percepção dos funcionários quanto aos benefícios, impactos da integração delas e também os níveis de adoção e internalização.

Os motivos da variabilidade dos resultados de um modelo de gestão em princípio padronizado, como é o modelo ISO 14001, foram pesquisados por Yin e Schmeidler (2009). Entre as conclusões importantes está o fato de que empresas que incluíam a gestão ambiental nas atividades do dia a dia relatavam melhor desempenho ambiental. Link e Haifa (2006) mostraram, na mesma direção, que quando as atividades ambientais são incluídas no dia a dia o desempenho ambiental melhora. Não conseguiram comprovar, no entanto, melhora no desempenho global dos negócios.

Conforme Boiral (2011), alguns exemplos de ações para a efetivação dos planos de gestão ambiental no dia a dia da empresa ocorrem por meio da aplicação de recursos, definição de regras ou procedimentos, definição de responsabilidades e autoridades, desenvolvimento de competências, habilidades e treinamento e processos de comunicação. Para o autor, a possibilidade de controlar e monitorar as ações definidas ocorre por documentos e processos de auditoria que devem ser regularmente avaliados sobre o que se espera como resultado de desempenho desse sistema de gestão.

\section{Comportamento Ambiental}

Para se compreender as escolhas ambientais de uma pessoa, variáveis individuais, como gênero, idade e experiências vivenciadas, devem ser consideradas de acordo com Tuan (2012). Neste sentido, é importante conhecer a relação de um grupo de funcionários com o meio ambiente, uma vez que estas informações indicam suas atitudes e comportamento ambiental, que são reflexos da percepção ambiental, ou seja, como as 
questões ambientais são sentidas e percebidas por um determinado grupo. Conforme Molina, Lui e Silva (2007), a ecologia humana pode contribuir com referenciais teóricos e metodológicos para a Gestão Ambiental. Desta forma, o estudo da adaptabilidade humana (flexibilidade nas respostas) está relacionado com a interação das pessoas com o meio, afetando diretamente os aspectos fisiológicos e comportamentais, partindo de um processo biológico e cultural.

Neste sentido, presume-se que o profissional que conduz as práticas ambientais dentro de uma empresa, adapta-se às condições e ferramentas necessárias para a empresa. Este condutor geralmente possui uma formação na área de administração, buscando, muitas vezes, associar ações sustentáveis ao retorno financeiro de interesse das empresas (FERREIRA et al., 2015). Segundo Whitmarsh (2009), o comportamento ambiental é resultante da interação das pessoas com a sociedade e pode tornar complexa a sua avaliação. Desta forma, existe uma relação entre as interações cotidianas e as atitudes com o meio ambiente.

França, Guimarães e Andrade (2015) buscaram identificar melhorias advindas da criação de um Programa de Educação Ambiental (PEA) em uma empresa em Manaus. Dos $93 \%$ funcionários que identificaram que a empresa realiza coleta seletiva, 46,7\% consideraram-se responsáveis por minimizar problemas ambientais. Estes programas são importantes, pois trabalham com informação, sensibilização e conscientização de um grupo de colaboradores, almejando mudanças no comportamento em relação ao meio ambiente.

No caso da certificação ISO 14001, espera-se que os trabalhadores tenham um comportamento ambiental alinhado com a política ambiental da organização. Para atingir isso, a organização deve adotar procedimentos para garantir que os trabalhadores sejam competentes e que estejam conscientizados de suas funções no sistema de gestão, dos aspectos ambientais significativos e da importância do seu desempenho pessoal para que a empresa atinja seus objetivos ambientais (ASSOCIAÇÃO..., 2004).

Daily e Huang (2001), Jabbour e Santos (2008) e Renwick, Redman e Maguire (2012), concluíram que o sucesso na aplicação de um Sistema de Gestão Ambiental depende de seus Recursos Humanos $(\mathrm{RH})$, e apresentaram o treinamento como um importante item do RH. O treinamento ambiental é um dos fatores essenciais na motivação dos envolvidos em um sistema de gestão ambiental (GOVINDARAJULU; DAILY, 2004). Estes autores destacam que treinamento insuficiente resulta em falta de envolvimento e motivação, comprometendo os resultados esperados em um Sistema de Gestão Ambiental. Para que seja possível a inserção da Educação Ambiental (EA), é fundamental que a empresa tenha um profissional qualificado que conheça suas práticas ambientais para que este seja responsável por apontar e mediar os processos educativos.

Em 1995 foi criada no Brasil a Política Nacional de Educação Ambiental (PNEA) e, desde então, vem sendo aperfeiçoada e inserida em todos os setores. A EA tornou-se uma prática que deve estar inserida nos ambientes empresariais, principalmente pelo estabelecimento do SGA, exigido pelas normas de Certificação ISO 14000. De acordo com Pedrini e Pelliccione (2007), porém, não há preocupação em se buscar qualidade na EA tanto pelo SGA quanto pela Gestão da Qualidade. Não são relatadas estratégias metodológicas para atingir os objetivos da EA nas empresas, como, por exemplo, obser- 
vação participante. Em suma, as dificuldades metodológicas para execução e avaliação da EA podem ser minimizadas com aperfeiçoamento profissional de educadores ambientais.

Jabbour (2013) realizou uma pesquisa empírica para comparar a aplicação das ferramentas de gestão de treinamento ambiental com a maturidade das empresas, proposta pela norma ISO 10015 de gestão da qualidade, que aborda as diretrizes para treinamento. Como resultado, demonstrou a relação entre os construtos estudados e concluiu que o investimento no treinamento ambiental contribui para a gestão do meio ambiente na empresa e também para o desempenho ambiental e fatores relacionados à gestão de pessoas e à Responsabilidade Social.

Entendendo que a aplicação dessas práticas desenvolve a cultura e o comportamento do trabalhador, essas podem também influenciar a forma de vida e o relacionamento deste trabalhador com as pessoas e o meio ambiente fora da organização. Campos e Pol (2010), realizaram pesquisa e puderam identificar que as empresas certificadas no Sistema de Gestão Ambiental ISO14001 influenciam os comportamentos pró-ambientais de seus trabalhadores, como na economia de água e luz, na limpeza, no ativismo/consumo e na reciclagem.

\section{MÉTODOS E TÉCNICAS}

Uma vez estabelecido o problema de pesquisa e o seu objetivo, foi constituído o modelo de pesquisa e de coleta de dados a fim de identificar as práticas ambientais e a frequência com que essas são realizadas pelos trabalhadores.

Utilizou-se uma survey (HAIR et al., 2005) constituída por assertivas com respostas em escala Likert, na qual o respondente escolhia uma entre cinco opções possíveis: discordo totalmente; discordo; nem discordo, nem concordo; concordo; e concordo totalmente. O questionário também apresentava perguntas para levantamento do perfil do respondente.

Os dados da pesquisa estruturada permitiram a realização de avaliação quantitativa com a análise de correlação dos dados (HAIR et al., 2005). Por meio do método de triangulação, os levantamentos quantitativos foram comparados com os levantamentos qualitativos obtidos pelo método de estudo de caso (YIN, 2005) e também com o referencial teórico apresentado.

O método de triangulação permite olhar para um mesmo fenômeno a partir de diferentes ângulos e tem como objetivo a descoberta de dimensões desviantes, a sintetização e a integração das teorias, auxiliando na validação dos resultados (AZEVEDO et al., 2013; VERGARA, 2006).

\section{Caracterização do Contexto do Estudo - a empresa}

A coleta de dados para o estudo foi feita com a participação de colaboradores de uma indústria do ramo químico que realiza serviços de tratamento superficial de peças metálicas. Trata-se de uma empresa familiar fundada em 1991 e localizada no município de Piracaia, interior de São Paulo. Na época da coleta de dados da pesquisa a empresa contava com 234 colaboradores com jornada de trabalho distribuída em dois turnos de produção e um turno administrativo. 
A empresa fornece serviços de tratamento superficial de peças pelo processo de anodização. Dentre os serviços oferecidos destacam-se: anodização dura - com camadas altas e com alta dureza; anodização dura colorida; sinergístico - canonização dura com PTFE; anodização dura com baixíssima rugosidade; anodização dura em ligas fundidas e injetadas com ou sem baixa rugosidade; e anodização natural fosca. Seus principais clientes são empresas montadoras e fornecedoras de peças do ramo automobilístico.

O processo de anodização baseia-se na aplicação de peças em tanques com água e soluções químicas para que essas sejam tratadas superficialmente. Os principais aspectos são o uso de grandes volumes de água e o descarte de efluentes industriais contendo metais e soluções químicas, além do consumo de energia elétrica necessário para o funcionamento de máquinas e equipamentos.

Em atendimento a requisitos de qualidade e de meio ambiente, a empresa possui certificação de seu sistema de gestão da qualidade nas normas ISO 9001 e ISO/TS 16949 e sistema de gestão ambiental ISO 14001. A empresa foi escolhida por possuir um programa de treinamento de colaboradores voltado ao desenvolvimento ambiental e também pela permissão e o acesso às plantas industriais e à documentação do Sistema de Gestão.

\section{Desenvolvimento do Questionário}

O desenvolvimento e a validação do questionário ocorreram com a aplicação do método Lawshe (1975). Após definidas as assertivas que poderiam ser utilizadas na pesquisa, essas foram encaminhadas para pessoas com conhecimento acadêmico ou profissional em Sistema de Gestão Ambiental ISO 14001. Em cada uma das 35 assertivas, cada painelista respondeu se a assertiva avaliada era essencial, ou útil mas não importante, ou não essencial para avaliar cada uma das dimensões. Dentre as dimensões estão: comportamento ambiental na empresa, comportamento ambiental em casa, relação entre comportamento na empresa e em casa.

Foram obtidas respostas de 13 avaliações dentre as 30 encaminhadas. Esses questionários foram analisados para validação das assertivas conforme critério de Ayre e Scally (2014), e 10 delas foram validadas para avaliação das dimensões definidas. A aplicação deste critério utilizou como base a fórmula Content Validity Ratio (CVR) de Lawshe (1975), como segue, e seu resultado analisado na Tabela 1, relacionando a quantidade de respondentes com a quantidade mínima de questões com resposta essencial por assertiva.

$$
C V R=\frac{n_{e}-(N / 2)}{N / 2}
$$

onde $n_{e}$ é o número de assertivas apontadas como essenciais pelos painelistas e $\mathrm{N}$ o número de painelistas. 
Tabela 1 - Tabela Simplificada do CVR crítico incluindo número de conhecedores necessários para considerar a assertiva essencial

\begin{tabular}{c|c|c|c}
\hline № Respondentes & $\begin{array}{c}\text { № critico (Quantidade Mínima de } \\
\text { Especialistas que consideraram a } \\
\text { assertiva essencial para inclusão) }\end{array}$ & Proporção Essencial & CVR Crítico \\
\hline 5 & 5 & 1 & 1.00 \\
\hline 6 & 6 & 1 & 1.00 \\
\hline 7 & 7 & 1 & 1.00 \\
\hline 8 & 7 & .875 & .750 \\
\hline 9 & 8 & .889 & .778 \\
\hline 10 & 9 & .900 & .800 \\
\hline 11 & 9 & .818 & .636 \\
12 & 10 & .833 & .667 \\
\hline
\end{tabular}

Fonte: AYRE; SCALLY, 2014.

\section{Aplicação do Questionário}

Passou-se, então, para a fase de aplicação dos questionários, a qual ocorreu em uma empresa certificada pelo sistema de gestão ambiental ISO 14001. A aplicação dos questionários ocorreu em um único dia e em todos os turnos de trabalho e setores na empresa. Estavam envolvidas na aplicação duas pessoas. Em cada um dos setores foram reunidos os colaboradores, que foram orientados sobre os objetivos e propósitos da avaliação, sendo esclarecidas as dúvidas surgidas para seu preenchimento.

A amostra constituiu na aplicação de 147 questionários. Um dos pesquisadores, acompanhado da gestora de meio ambiente na empresa, percorreu os setores reunindo os profissionais e orientando-os sobre os objetivos e método de preenchimento do questionário. A coleta se deu nos dois períodos ou turnos de trabalho, conforme a quantidade informada de respondentes. A aplicação ocorreu em todos os setores e níveis da empresa e também em todos os turnos de trabalho.

\section{Análise Estatística dos Resultados}

As respostas aos questionários foram processadas com o auxílio do software SPSS. Foi feito um estudo das correlações bivariadas entre cada uma das respostas. Para a análise estatística foram utilizadas técnicas de análise univariadas, como teste de normalidade e estimativas de média e desvio padrão e análise de correlação bivariada (HAIR et al., 2005). Dessa forma, foram considerados significativos os resultados que apresentaram $p>0,05$. Posteriormente as correlações foram destacadas nos resultados.

\section{Informações Complementares}

De forma complementar ao questionário aplicado, observou-se fatores organizacionais relacionados ao Sistema de Gestão Ambiental por meio de análise qualitativa com a aplicação de modelo de Estudo de Caso proposto por Yin (2005). As fontes de informação utilizadas estão descritas no Quadro 1. 
Quadro 1 - Fontes de informações e atividades

\begin{tabular}{|l|l|}
\hline Fonte & Atividades \\
\hline Documentos & $\begin{array}{l}\text { Visita ao escritório. Buscou-se documentos sobre atendimento a requisitos legais e } \\
\text { procedimentos internos documentados }\end{array}$ \\
\hline Registros & $\begin{array}{l}\text { Registros de treinamento, evidências de atendimento, gráficos e tabelas com } \\
\text { indicadores ambientais. }\end{array}$ \\
\hline Entrevistas & $\begin{array}{l}\text { Semiestruturadas com a representante da direção no Sistema de Gestão Ambiental. } \\
\text { Tópicos abordados: } \\
\text { - métodos de avaliação comportamental ligados ao meio ambiente dentro da empresa } \\
\text { - métodos empregados pela empresa para análise da eficácia das ações empregadas } \\
\text { - estrutura do sistema de gestão ambiental } \\
\text { • histórico ambiental da empresa }\end{array}$ \\
\hline $\begin{array}{l}\text { Aparatos } \\
\text { físicos }\end{array}$ & $\begin{array}{l}\text { Visita a instalações da empresa: produção, escritório, oficinas, área de manuseio de } \\
\text { resíduos, tratamento de efluentes e outros controles ambientais. }\end{array}$ \\
\hline $\begin{array}{l}\text { Observação } \\
\text { direta }\end{array}$ & $\begin{array}{l}\text { Durante a visita, observação das práticas dos funcionários no dia a dia da coleta } \\
\text { seletiva, uso de registros, controles ambientais, aplicação de procedimentos para } \\
\text { atender às necessidades dos aspectos ambientais considerados significativos em cada } \\
\text { setor, consumo de água, consumo de energia, entre outros. }\end{array}$ \\
\hline $\begin{array}{l}\text { Observação } \\
\text { participante }\end{array}$ & $\begin{array}{l}\text { O pesquisador passou pelo mesmo treinamento de integração aplicado aos novos } \\
\text { funcionários }\end{array}$ \\
\hline
\end{tabular}

Fonte: Os autores.

\section{RESULTADOS}

Os resultados são apesentados em três partes: o perfil dos respondentes, a análise estatística dos questionários e as informações complementares para análise dos resultados.

\section{Perfil dos Respondentes}

A Tabela 2 fornece informações coletadas sobre os respondentes, predominando os homens, funcionários operacionais e com Ensino Médio.

Tabela 2 - Distribuição Hierárquica dos Cargos e Escolaridade

\begin{tabular}{|c|c|c|c|}
\hline Item & Classificação & Número & $\%$ \\
\hline \multirow{4}{*}{ Distribuição Cargos } & Operacional & 114 & 77,6 \\
\hline & Líderes e Supervisores & 12 & 8,2 \\
\hline & Gerentes & 4 & 2,7 \\
\hline & Administração & 17 & 11,6 \\
\hline \multirow{6}{*}{ Escolaridade } & Fundamental Incompleto & 8 & 5,4 \\
\hline & Fundamental Completo & 12 & 8,2 \\
\hline & Ensino Médio Incompleto & 18 & 12,2 \\
\hline & Ensino Médio Completo & 81 & 55,1 \\
\hline & Superior Incompleto & 15 & 10,2 \\
\hline & Superior Completo & 13 & 8,8 \\
\hline \multirow{2}{*}{ Gênero } & Masculino & 78 & 53,1 \\
\hline & Feminino & 69 & 46,9 \\
\hline
\end{tabular}

Fonte: Os autores. 
A Tabela 3 fornece informações coletadas sobre a descrição dos funcionários em relação aos locais em que vivem referente à infraestrutura e saneamento, se possui veículo próprio e também a forma de deslocamento de casa para o trabalho.

Tabela 3 - Caracterização dos entrevistados da empresa, em relação aos locais que vivem

\begin{tabular}{lllc}
\hline \multicolumn{1}{c}{ Item } & \multicolumn{1}{c}{ Classificação } & Número & $\%$ \\
\hline \multirow{2}{*}{ Rua Asfaltada } & Sim & 83 & 79,8 \\
\cline { 2 - 4 } & Não & 21 & 20,2 \\
\hline \multirow{2}{*}{ Veículo Próprio } & Sim & 91 & 61,9 \\
\cline { 2 - 4 } & Não & 56 & 38,1 \\
\hline \multirow{2}{*}{ Nuto ou Moto } & Nunca & 19 & 12,9 \\
\cline { 2 - 4 } & Algumas Vezes & 43 & 29,3 \\
\cline { 2 - 4 } & Habitualmente & 27 & 18,4 \\
\cline { 2 - 4 } & Sempre & 58 & 39,5 \\
\hline \multirow{2}{*}{ Água Encanada } & Sim & 143 & 97,3 \\
\cline { 2 - 4 } & Não & 4 & 2,7 \\
\hline \multirow{2}{*}{ Local da Residência } & Casa Cidade & 131 & 89,1 \\
\cline { 2 - 4 } & Área rural & 16 & 10,9 \\
\hline Serviço de Esgoto & Rede Coletiva & 123 & 83,7 \\
\cline { 2 - 4 } & Rede Individual & 24 & 16,3 \\
\hline
\end{tabular}

Fonte: Os autores.

\section{Comportamento Ambiental Declarado}

Os 147 questionários foram tabulados e os resultados gerais estão identificados na Tabela 4. Foi realizado teste de normalidade e todas as assertivas de Q1 a Q35, bem como as variáveis demográficas idade e tempo de empresa, resultaram não normais. Em virtude disso, os testes de correlação realizados utilizaram o coeficiente de correlação de Spearman (HAIR et al., 2005).

Tabela 4 - Estatísticas descritivas das respostas as questões

\begin{tabular}{|c|c|c|c|}
\hline cod & Texto da assertiva & Média & $\begin{array}{l}\text { Desvio } \\
\text { padrão }\end{array}$ \\
\hline Q1 & $\begin{array}{l}\text { Economizo energia elétrica na minha casa para contribuir para a melhoria } \\
\text { do meio ambiente. }\end{array}$ & 4,26 & ,767 \\
\hline Q2 & $\begin{array}{l}\text { Estamos nos aproximando do número máximo de pessoas que a Terra pode } \\
\text { suportar. }\end{array}$ & 3,43 & 1,090 \\
\hline Q3 & $\begin{array}{l}\text { A empresa em que trabalho preocupa-se verdadeiramente com o meio } \\
\text { ambiente. }\end{array}$ & 3,97 & ,727 \\
\hline Q4 & O equilíbrio da natureza é muito delicado e facilmente perturbado. & 4,21 & ,761 \\
\hline Q5 & A empresa em que trabalho recicla os resíduos gerados por ela. & 4,29 & ,787 \\
\hline Q6 & $\begin{array}{l}\text { Os seres humanos têm o direito de modificar o ambiente natural para } \\
\text { atender as suas necessidades. }\end{array}$ & 2,51 & 1,290 \\
\hline Q7 & $\begin{array}{l}\text { Os resíduos da empresa em que trabalho são separados e destinados para } \\
\text { locais adequados. }\end{array}$ & 4,07 & 997 \\
\hline Q8 & A humanidade foi criada para governar o resto da natureza. & 2,50 & 1,278 \\
\hline Q9 & Minha empresa se preocupa com o consumo de energia elétrica. & 4,02 & 974 \\
\hline
\end{tabular}




\begin{tabular}{|c|c|c|c|}
\hline $\operatorname{cod}$ & Texto da assertiva & Média & $\begin{array}{l}\text { Desvio } \\
\text { padrão }\end{array}$ \\
\hline Q10 & $\begin{array}{l}\text { A humanidade não precisa se adaptar ao ambiente natural porque pode } \\
\text { modificá-lo para atender as suas necessidades. }\end{array}$ & 2,30 & 1,101 \\
\hline Q11 & Minha empresa se preocupa com o consumo de água. & 3,97 & 1,007 \\
\hline Q12 & $\begin{array}{l}\text { Para manter um meio ambiente saudável, teremos de controlar o } \\
\text { crescimento econômico. }\end{array}$ & 3,53 & 1,085 \\
\hline Q13 & $\begin{array}{l}\text { Sou motivado pela empresa em que trabalho a reduzir o consumo de } \\
\text { energia elétrica. }\end{array}$ & 3,98 & ,781 \\
\hline Q14 & A poluição do ar na minha cidade é algo que me preocupa muito. & 3,50 & 1,099 \\
\hline Q15 & Sou motivado pela empresa em que trabalho a reduzir o consumo de água. & 3,96 & ,812 \\
\hline Q16 & $\begin{array}{l}\text { A destinação do lixo urbano deve receber atenção permanente dos } \\
\text { administradores públicos }\end{array}$ & 4,42 & ,683 \\
\hline Q17 & $\begin{array}{l}\text { A empresa em que trabalho preocupa-se com o manuseio dos produtos } \\
\text { químicos. }\end{array}$ & 4,34 & ,742 \\
\hline Q18 & O crescimento urbano é cada vez mais prejudicial ao meio ambiente. & 3,98 & ,895 \\
\hline Q19 & $\begin{array}{l}\text { Recebo constantemente na empresa orientações sobre como não poluir o } \\
\text { meio ambiente. }\end{array}$ & 3,96 & ,794 \\
\hline Q20 & Devo utilizar o transporte público para ajudar o meio ambie & 3,33 & 1,145 \\
\hline Q21 & Aprendi na empresa a economizar energia. & 3,35 & 1,082 \\
\hline Q22 & $\begin{array}{l}\text { A facilidade de descarte ou reciclagem deve sempre ser considerada no } \\
\text { momento da compra de um produto. }\end{array}$ & 3,73 & 903 \\
\hline Q23 & Aprendi na empresa a economizar água. & 3,17 & 1,128 \\
\hline Q24 & $\begin{array}{l}\text { A durabilidade de um produto reduz seu impacto ambiental, mesmo que } \\
\text { ele custe mais caro. }\end{array}$ & 3,55 & ,962 \\
\hline Q25 & Aprendi na empresa a preocupar-me com o meio ambiente. & 3,42 & 1,149 \\
\hline Q26 & $\begin{array}{l}\text { Um certificado que indique, por exemplo, que um produto foi feito } \\
\text { seguindo normas ambientais, auxilia na minha decisão de compra. }\end{array}$ & 3,91 & ,882 \\
\hline Q27 & $\begin{array}{l}\text { No que diz respeito ao meio ambiente, vejo que a empresa em que trabalho } \\
\text { se preocupa com as próximas gerações. }\end{array}$ & 3,88 & ,805 \\
\hline Q28 & $\begin{array}{l}\text { As empresas devem ser incentivadas a utilizar matéria-prima reciclada } \\
\text { como uma forma de reduzir o seu impacto ambiental. }\end{array}$ & 4,19 & 809 \\
\hline Q29 & $\begin{array}{l}\text { Sinto-me estimulado a uma atitude ambientalmente correta quando vejo a } \\
\text { postura da diretoria da empresa. }\end{array}$ & 3,68 & 848 \\
\hline Q30 & $\begin{array}{l}\text { Sinto-me estimulado a uma atitude ambientalmente correta quando vejo a } \\
\text { postura dos líderes da empresa. }\end{array}$ & 3,63 & 849 \\
\hline Q31 & Usei os exemplos da empresa para economizar água em casa. & 3,10 & 1,107 \\
\hline Q32 & Usei os exemplos da empresa para economizar energia em casa. & 3,17 & 1,141 \\
\hline Q33 & Usei os exemplos da empresa para separar os resíduos na minha casa. & 3,23 & 1,038 \\
\hline Q34 & Descarto em locais corretos pilhas e baterias que uso em casa. & 3,58 & 1,090 \\
\hline Q35 & $\begin{array}{l}\text { Descarto em locais corretos óleo que uso em casa para fritura e preparação } \\
\text { de alimentos. }\end{array}$ & 3,77 & 1,188 \\
\hline
\end{tabular}

Fonte: Os autores.

Em relação à confiabilidade geral da escala, o alfa de Cronbach resultou 0,826, o que está na faixa aceitável acima de 0,7, conforme recomendado por Hair et al. (2005). O alfa para as questões exclusivas do construto "atitude em casa" resultou 0,596; "prá- 
ticas ambientais da empresa" foi 0,806, e para a "aprendizado com a empresa" 0,865. Nota-se que potenciais problemas poderiam ocorrem no construto "atitude em casa", uma vez que, para estudos exploratórios, o alfa mínimo recomendado é de 0,6, o qual seria atingido apenas por arredondamento. A decisão dos pesquisadores foi de continuar, mesmo estando esse número no limite.

Atentos a essa questão, foram realizados testes de correlação bivariada entre as respostas às assertivas do construto "atitude em casa" com "práticas ambientais da empresa" e "aprendizado com a empresa". As correlações entre as questões do construto "atitude em casa" com "práticas ambientais da empresa", estão na Tabela 5. Já as correlações entre atitude ambiental do funcionário e a percepção do quanto as práticas da empresa influenciam essa atitude, são apresentadas na Tabela 6 .

Tabela 5 - Correlações entre atitude ambiental do funcionário e práticas ambientais percebidas na empresa

\begin{tabular}{|c|c|c|c|c|c|c|c|c|c|c|c|c|c|c|c|c|c|c|}
\hline \multirow{2}{*}{\multicolumn{2}{|c|}{$\begin{array}{l}\text { Práticas } \\
\text { da } \\
\text { empresa }\end{array}$}} & \multicolumn{17}{|c|}{ Atitude ambiental do funcionário } \\
\hline & & Q1 & Q2 & Q4 & Q6 & Q8 & Q10 & $\mathrm{Q} 12$ & Q14 & Q16 & Q18 & Q20 & Q22 & Q24 & Q26 & Q28 & Q34 & Q35 \\
\hline \multirow{3}{*}{ Q3 } & $\rho$ & 122 &,- 049 &,- 057 & $\begin{array}{c}- \\
168^{*}\end{array}$ & 063 &,- 098 &,- 085 &,- 002 &,- 032 & -002 & ,076 &,- 123 & -128 & $163^{*}$ & 090 & $191^{\circ}$ &, 045 \\
\hline & $p$ & 141, & ,555 & 496, & ,042 & 449 & 236 & 308, & 983, & 700 & 984 & 359, & 137, & 122 & ,049, & 279, & ,020 & ,588 \\
\hline & $\mathrm{N}$ & 147 & 147 & 147 & 147 & 147 & 147 & 147 & 147 & 147 & 147 & 147 & 147 & 147 & 147 & 147 & 147 & 147 \\
\hline \multirow{3}{*}{ Q5 } & $\rho$ & 069 & -017 & ,219* & -124 & -071 &,$- 180^{\circ}$ &,- 015 & 025 & 108 & 114 & 125 &,- 019 & ,028 & 143 &, $214^{* *}$ & 096 &, $166^{\circ}$ \\
\hline & $p$ & 403, & ,838 & , 008 & 135 & 390 & ,029 & 861 & ,767 & 192 & 170, & 130, & 817 & ,733 & 085, & 009, & 247 &, 045 \\
\hline & $\mathrm{N}$ & 147 & 147 & 147 & 147 & 147 & 147 & 147 & 147 & 147 & 147 & 147 & 147 & 147 & 147 & 147 & 147 & 147 \\
\hline \multirow{3}{*}{ Q7 } & $\rho$ & 021 & -019 & ,075 & $\overline{-}^{-}, 168^{*}$ & -127 & $\bar{\sigma}^{-}, 276^{*}$ &,- 153 &, 040 & 021 &,- 053 & 095 &,- 114 &,- 098 & $198^{*}$ & ,304** & ,224** & 153 \\
\hline & $p$ & 798, & 818 & 367, & ,043 & 129, & 001 & 066 & 630, & 799, &, 530 & 255, & 173 & 242 & ,017 & ,000 & ,007 & ,066 \\
\hline & $\mathrm{N}$ & 145 & 145 & 145 & 145 & 145 & 145 & 145 & 145 & 145 & 145 & 145 & 145 & 145 & 145 & 145 & 145 & 145 \\
\hline \multirow{3}{*}{ Q9 } & $\rho$ & 065, & 118 & 147, & ,075, & ,006 &,$- 208^{\circ}$ & -,048 & ,022 & $165^{\circ}$ & ,062 & $190^{\circ}$ & ,045 & ,093 & "279** &, $256^{* *}$ & $180^{\circ}$ & 145, \\
\hline & $p$ & 431 & 154, & , 075 & ,364 & 943, & ,012 & ,561 & ,792 & ,045 & 455 & 021 & ,592 & 263 & ,001 & ,002 & ,029 & 079, \\
\hline & $\mathrm{N}$ & 147 & 147 & 147 & 147 & 147 & 147 & 147 & 147 & 147 & 147 & 147 & 147 & 147 & 147 & 147 & 147 & 147 \\
\hline \multirow{3}{*}{ Q11 } & $\rho$ & 146, & ,008 & ,023 & 127, & ,074 & 108 & -,018 & -014 & ,073 & ,030 & $188^{\circ}$ & -075 & ,053 & 123, & , 220"* & $179^{\circ}$ & ,084 \\
\hline & $p$ & 079, & 924 & 778, & 127 & 377, & 192 & 831 & ,866 & ,381 & ,722 & ,023 & ,366 & ,523 & 139, & ,008 & ,031 & ,311 \\
\hline & $\mathrm{N}$ & 146 & 146 & 146 & 146 & 146 & 146 & 146 & 146 & 146 & 146 & 146 & 146 & 146 & 146 & 146 & 146 & 146 \\
\hline \multirow{3}{*}{ Q17 } & $\rho$ & 161 & -022 & 136, & -077, & -,044 &,$- 176^{\circ}$ & ,005 & 160 & , 254** & 133, & 135, &,- 051 & -,016 & $169^{\circ}$ & , & 107, & 116, \\
\hline & $p$ & 051 & 793, & 100, & ,352 & 593 & 033 & 955 & 053 &, 002 & 109, & 103, & 539 & ,851 & ,041 & ,000 & 199, & 161 \\
\hline & $\mathrm{N}$ & 147 & 147 & 147 & 147 & 147 & 147 & 147 & 147 & 147 & 147 & 147 & 147 & 147 & 147 & 147 & 147 & 147 \\
\hline \multirow{3}{*}{ Q27 } & $\rho$ & 077, & 104 & 132 & ,125 & 111 & -062 & -006 & -019 & ,057 & (177" & , $209^{\circ}$ & 118 & -050 & ,391** & ,244" & , & * \\
\hline & $p$ & 351, & 209, & 111, & 130, & 180, & ,454 & 947, &, 820 & 492 & ,032 & 011, & 156, & ,549 & ,000 & ,003 & ,000 & ,004 \\
\hline & $\mathrm{N}$ & 147 & 147 & 147 & 147 & 147 & 147 & 147 & 147 & 147 & 147 & 147 & 147 & 147 & 147 & 147 & 147 & 147 \\
\hline
\end{tabular}


Nota-se primeiro que, embora as correlações existam, nenhum dos coeficientes de correlação encontrados foi superior a 0,4 , indicando que as correlações são de fracas a moderadas. Nota-se que as assertivas "Um certificado que indique, por exemplo, que um produto foi feito seguindo normas ambientais auxilia na minha decisão de compra"; "As empresas devem ser incentivadas a utilizar matéria-prima reciclada como uma forma de reduzir o seu impacto ambiental" e "Descarto em locais corretos pilhas e baterias que uso em casa", foram as que se correlacionaram com um maior número de assertivas relativas às práticas da empresa. Por um lado, a prática de destinação de pilhas e baterias é uma das práticas reforçadas com a introdução de Sistemas de Gestão Ambiental ISO 14001, o que é consistente com a realidade encontrada; por outro, as duas outras assertivas são mais conceituais, refletindo um conhecimento geral do funcionário sobre temas que podem se tornar presentes no seu dia a dia.

Cabe ressaltar, ainda, que as práticas da empresa que se correlacionaram com um número maior de assertivas sobre a atitude ambiental em casa foram as questões "Os resíduos da empresa que trabalho são separados e destinados para locais adequados", "Minha empresa se preocupa com o consumo de energia elétrica" e "No que diz respeito ao meio ambiente vejo que a empresa em que trabalho se preocupa com as próximas gerações".

Tabela 6 - Correlações entre atitude ambiental do funcionário e a percepção do quanto as práticas da empresa influenciam essa atitude

\begin{tabular}{|c|c|c|c|c|c|c|c|c|c|c|c|c|c|c|c|c|c|c|}
\hline \multirow{2}{*}{ 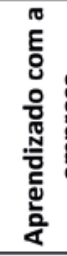 } & \multirow{2}{*}{ 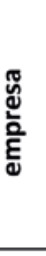 } & \multicolumn{17}{|c|}{ Atitude ambiental do funcionário } \\
\hline & & Q1 & Q2 & Q4 & Q6 & Q8 & Q10 & Q12 & Q14 & Q16 & Q18 & Q20 & Q22 & Q24 & Q26 & Q28 & Q34 & Q35 \\
\hline & $\rho$ & ,191* & -,009 &,- 006 & -,089 & ,031 &,- 043 &, 005 &,- 010 & ,234** & ,079 & ,011 & ,020 &,- 037 & 138 & 157 & $180^{*}$ & ,056 \\
\hline \multirow[t]{3}{*}{ Q13 } & $p$ & ,022 & 916 & 945 & 285 & 714 & 604 & 950 & 904 & ,005 & 345 & ,895 & ,816 & ,655 & ,098 & ,060 & ,031 & ,505 \\
\hline & $\mathrm{N}$ & 145 & 145 & 145 & 145 & 145 & 145 & 145 & 145 & 145 & 145 & 145 & 145 & 145 & 145 & 145 & 145 & 145 \\
\hline & $\rho$ & $206^{\circ}$ & 109 & ,000 & ,029 & ,097 & -077 & -100 & 017 & $204^{*}$ & ,043 & ,020 & ,067 &,- 093 & ,095 & ,201* & "218" & 131 \\
\hline \multirow[t]{3}{*}{ Q15 } & $\mathrm{p}$ & 013 & 192 & 997 & ,725 & 247 & ,354 & ,229 & 842 &, 014 & 607 & ,811 & ,426 &, 264 & 253 & ,015 &, 008 & 116 \\
\hline & $\mathrm{N}$ & 145 & 145 & 145 & 145 & 145 & 145 & 145 & 145 & 145 & 145 & 145 & 145 & 145 & 145 & 145 & 145 & 145 \\
\hline & $\rho$ & 137 &,- 031 &,- 117 & $194^{\circ}$ & 108 & , 108 & ,046 & ,080 & 113 & ,088 & ,294** & ,090 &,- 005 & $254^{* *}$ & ,069 & , $247^{* *}$ & 178* \\
\hline \multirow[t]{3}{*}{ Q19 } & $\mathrm{p}$ & 100 & ,716 & ,164 & 020 & 196 & ,200 &, 584 & ,339 & 177 &, 294 & ,000 & ,282 & ,953 & 002 & ,411 &, 003 & 033 \\
\hline & $\mathrm{N}$ & 144 & 144 & 144 & 144 & 144 & 144 & 144 & 144 & 144 & 144 & 144 & 144 & 144 & 144 & 144 & 144 & 144 \\
\hline & $\rho$ & 039 &, $172^{*}$ &,- 052 &,- 006 & 097 & 049 &,- 062 &,- 052 &,- 038 &,- 062 & 079 & ,131 &, 032 & 086 & -017 & $174^{*}$ & ,082 \\
\hline \multirow[t]{3}{*}{ Q21 } & $\mathrm{p}$ & 636 & ,038 & ,529 & ,939 & 244 & ,557 & ,457 & ,535 & 649 & ,456 & 344 & 112 & ,699 & 299 & ,838 & ,035 & ,325 \\
\hline & $\mathrm{N}$ & 147 & 147 & 147 & 147 & 147 & 147 & 147 & 147 & 147 & 147 & 147 & 147 & 147 & 147 & 147 & 147 & 147 \\
\hline & $\rho$ & ,009 & 151 &,- 037 & -,006 & -042 & ,057 & -,106 & -,131 & -,077 & -,028 & ,064 & 118 & ,111 & $187^{*}$ & 103 & $203^{*}$ & 119 \\
\hline \multirow[t]{3}{*}{ Q23 } & $\mathrm{p}$ & 910 & ,070 & ,654 & ,942 & 611 & ,495 & 202 & ,114 & ,356 & ,736 & ,439 & 156 & ,184 & ,024 & 214 &, 014 & 151 \\
\hline & $\mathrm{N}$ & 146 & 146 & 146 & 146 & 146 & 146 & 146 & 146 & 146 & 146 & 146 & 146 & 146 & 146 & 146 & 146 & 146 \\
\hline & $\boldsymbol{\rho}$ & ,000 & ,025 &, 044 & -,039 &,- 015 & ,052 & -056 &,- 083 & ,027 & ,021 & ,127 &, $166^{\circ}$ & $185^{\circ}$ & 239** & ,098 & $203^{*}$ & $177^{*}$ \\
\hline \multirow[t]{2}{*}{ Q25 } & $\mathrm{p}$ & 998, & ,762 & ,600 & 637 & ,856 & ,530 & ,505 & ,320 & ,750 & ,804 & ,126 & ,045 & ,025 & ,004 & 238 & ,014 &, 032 \\
\hline & $\mathrm{N}$ & 146 & 146 & 146 & 146 & 146 & 146 & 146 & 146 & 146 & 146 & 146 & 146 & 146 & 146 & 146 & 146 & 146 \\
\hline
\end{tabular}




\begin{tabular}{|c|c|c|c|c|c|c|c|c|c|c|c|c|c|c|c|c|c|c|}
\hline \multirow{2}{*}{\multicolumn{2}{|c|}{ 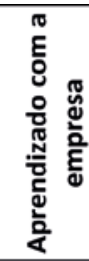 }} & \multicolumn{17}{|c|}{ Atitude ambiental do funcionário } \\
\hline & & Q1 & Q2 & Q4 & Q6 & Q8 & Q10 & Q12 & Q14 & Q16 & Q18 & Q20 & Q22 & Q24 & Q26 & Q28 & Q34 & Q35 \\
\hline \multirow{3}{*}{ Q29 } & $\rho$ &, $164^{\circ}$ &,- 019 & ,004 &,- 067 &,- 013 & -078 &,- 039 & 054 & 064 & 062 &, $264^{*}$ & ,137 & $190^{\circ}$ & $316^{*}$ &, $282^{*}$ &, $232^{*}$ & , 191* \\
\hline & $\mathrm{p}$ & 047 & 819 & 958 & ,423 & 877 &, 345 & 642 & ,519 & ,443 &, 453 &, 001 & 098 &, 021 &, 000 &, 001 & 005 & 020 \\
\hline & $\mathrm{N}$ & 147 & 147 & 147 & 147 & 47 & 147 & 147 & 47 & 47 & 147 & 147 & 147 & 147 & 147 & 147 & 147 & 147 \\
\hline \multirow{3}{*}{ Q30 } & $\rho$ & ,231* & -,010 & - 012 & |-059, & ,093 & ,018 & ,027 & ,124 & ,034 & 055 & , $319^{*}$ & ,302* & ,115 & ,377** & $240^{*}$ & ,233** & $248^{*}$ \\
\hline & $\mathrm{p}$ & ,005 & 905, & 890 & 476 & 261 &, 825 & 743 & 135 & 686, & ,509 & ,000 &, 000 & 164 &, 000 & ,003 & ,005 & ,002 \\
\hline & $\mathrm{N}$ & 147 & 147 & 147 & 147 & 147 & 147 & 147 & 147 & 147 & 147 & 147 & 147 & 147 & 147 & 147 & 147 & 147 \\
\hline \multirow{3}{*}{ Q31 } & $\rho$ &,- 052 & 051 & 020 & 122 & 160 & 094 & 122 &,- 033 & -040 & , 005 & $169^{\circ}$ & .057 & $209^{\circ}$ & ,124 & 025 & 124 & 015 \\
\hline & $\mathrm{p}$ & ,534 & ,543 & ,807 & 140 & , 052 & ,259 & 142 & 690 & ,627 & 953 &, 040 & ,495 & 011 & , 136 & ,761 & 134 & 860 \\
\hline & $\mathrm{N}$ & 147 & 147 & 147 & 147 & 147 & 147 & 147 & 147 & 147 & 147 & 147 & 147 & 147 & 147 & 147 & 147 & 147 \\
\hline \multirow{3}{*}{ Q32 } & $\rho$ & -013 & ,009 & ,023 & ,079 & , 056 & ,016 & 121 & 019 & ,006 & ,007 & , & , 048 & , 219" &, $170^{\circ}$ & -033 & ,082 & 059 \\
\hline & $\mathrm{p}$ & 876 & 915 & ,783 & ,341 & ,500 & 852 & 145, & 822 & 947 & 937, & ,232 & ,560 & , 008 & , 040 & 695 & ,326 &, 480 \\
\hline & $\mathrm{N}$ & 147 & 147 & 147 & 147 & 147 & 147 & 147 & 147 & 147 & 147 & 41 & 147 & 47 & 147 & 147 & 147 & 147 \\
\hline \multirow{3}{*}{ Q33 } & $\rho$ & ,028 & -014 & ,078 & ,026 & ,055 & ,144 & ,057 & -021 & ,030 & 017 & 116 & ,208 & \begin{tabular}{|l|}
, $178^{\circ}$ \\
\end{tabular} & 136 & 137 &, $305^{*}$ & $242^{*}$ \\
\hline & $\mathrm{p}$ & ,737 & 868 & ,349 & 757, & ,509 & ,083 & 491 & ,805 & ,722 & 840 & 164, & ,012 & , 031 & 102 & ,098 & ,000 & ,003 \\
\hline & $\mathrm{N}$ & 146 & 146 & 146 & 146 & 146 & 146 & 146 & 146 & 146 & 146 & 146 & 146 & 146 & 146 & 146 & 146 & 146 \\
\hline
\end{tabular}

Notas: $\boldsymbol{\rho}$ = coeficiente de correlação de Spearman; $\boldsymbol{p}=$ nível de significância estatístico; $\mathrm{N}$ = número de respostas válidas da assertiva

Fonte: Os autores.

\section{Informações Complementares}

A obtenção de informações complementares, conforme visita realizada, está resumida no Quadro 2.

Quadro 2 - Fontes de dados e informações coletadas na empresa

\begin{tabular}{|l|l|}
\hline $\begin{array}{c}\text { Fonte de } \\
\text { dados }\end{array}$ & \multicolumn{1}{c|}{ Informações } \\
\hline Documentos & $\begin{array}{c}\text { - Procedimento interno que define o mapeamento de competências profissionais relacionadas ao } \\
\text { assunto meio ambiente, necessárias para garantir a conformidade das análises realizadas por ela } \\
\text { e também necessidade da realização de campanhas de conscientização ambiental que se referem } \\
\text { ao consumo de recursos naturais, tratamento dos itens organizacionais capazes de causar im- } \\
\text { pactos significativos ao meio ambiente e atendimento à política de meio ambiente da empresa. } \\
\text { - Folhetos de campanhas de redução de consumo de água e energia elétrica. }\end{array}$ \\
& $\begin{array}{l}\text { - Registros de treinamentos de integração realizados para todos os colaboradores que começam } \\
\text { a trabalhar na empresa. Os conteúdos dos treinamentos de integração incluem diversos tópicos, } \\
\text { tais como qualidade, segurança, recursos humanos (pagamentos, benefícios, etc.). Em meio a } \\
\text { esses temas, são abordados aspectos estruturais do sistema de gestão ambiental e apresentados } \\
\text { os objetivos e metas, incluindo a economia de água e energia na empresa. } \\
\text { - Registros de treinamentos aplicados em colaboradores de cada setor instruindo-os sobre os as- } \\
\text { pectos ambientais importantes, impactos ambientais potenciais da não aplicação de procedi- } \\
\text { mentos e métodos de atendimento a emergências. Aplicadas em períodos de auditoria ou em } \\
\text { campanhas de conscientização quando os indicadores apresentam valores divergentes aos ob- } \\
\text { jetivos traçados. }\end{array}$ \\
\hline
\end{tabular}




\begin{tabular}{|c|c|}
\hline ista & $\begin{array}{l}\text { - Avaliação comportamental ocorre por meio de ficha de descrição do cargo com requisitos am- } \\
\text { bientais de cada tarefa. O setor de Recursos Humanos, junto aos gestores de área e gestor am- } \\
\text { biental, define, com base na experiência, as competências a serem desenvolvidas. Os treinamen- } \\
\text { tos são aplicados conforme planejamento e análise da eficácia das competências desenvolvidas, } \\
\text { realizada de forma subjetiva pelo líder imediato do treinado; a empresa define um planejamento } \\
\text { do sistema de gestão e estabelece programas para atingi-lo. Os programas envolvem a orientação } \\
\text { e o desdobramento dos indicadores do sistema de gestão na empresa. } \\
\text { - A empresa possui área responsável pelo sistema de gestão que orienta e acompanha as ativida- } \\
\text { des operacionais e ajuda multiplicadores e auditores internos do sistema de gestão. } \\
\text { - A empresa possui todas as licenças e registros ambientais necessários para a operação, e recebe } \\
\text { auditorias de clientes, organismos certificadores e órgão ambiental. } \\
\text { - Tem indicadores ambientais ligados aos principais aspectos ambientais de suas atividades, que } \\
\text { são consumo de água e energia elétrica. A empresa também monitora a geração de resíduos } \\
\text { líquido e sólidos compostos por metais pesados. }\end{array}$ \\
\hline & $\begin{array}{l}\text { - Uso de coletores coloridos para descartes de resíduos } \\
\text { - Área de resíduos com cobertura e separação por tipo; } \\
\text { - Estação de tratamento de efluentes industriais } \\
\text { - Tanques para a captação de água de chuva } \\
\text { - Caçambas especiais para coleta de resíduo perigoso } \\
\text { - Sistema de coleta de vapores } \\
\text { - Instalação de banhos em áreas de contenção para evitar o vazamento de líquidos } \\
\text { - Piso impermeável na área da produção e em áreas sensíveis }\end{array}$ \\
\hline $\begin{array}{l}\text { Observaç } \\
\text { direta }\end{array}$ & $\begin{array}{l}\text { - Durante as visitas na empresa foi possível verificar as práticas ambientais realizadas por ela e } \\
\text { todas aquelas introduzidas para controle descritas nos itens anteriores, evidenciando a aplicação } \\
\text { das ações propostas em documentos, o atendimento por meio dos registros, além do uso dos } \\
\text { recursos disponíveis aos envolvidos. }\end{array}$ \\
\hline $\begin{array}{l}\text { Observação } \\
\text { participante }\end{array}$ & $\begin{array}{l}\text { - Durante o processo de entrevista, o pesquisador participou das atividades, recebeu treinamento } \\
\text { e esteve envolvido no dia do trabalhador, evidenciando a aplicação dos controles e ações propos- } \\
\text { tas pela empresa. }\end{array}$ \\
\hline
\end{tabular}

Fonte: Os autores.

\section{DISCUSSÃO}

A maioria dos funcionários reconhece, que, de algum modo, a empresa se preocupa com o meio ambiente, como no caso de atividades de reciclagem. Isso contribui para a visão de que, em algum grau, a atuação da empresa está na direção de aproveitamento dos recursos ressaltado por Sachs (1993) e da reciclagem de materiais (ELKINGTON, 1997).

Por outro lado, é de alguma forma surpreendente que a assertiva Q11, sobre o consumo de água, tenha tido pouco destaque nas correlações com a atitude dos funcionários, uma vez que $40 \%$ do volume de água utilizado no processo de produção provém de água de reuso, o que também está de acordo com Sachs (1993) e Elkington (1997). Talvez essa ação seja menos percebida, por exemplo, do que o consumo de energia elétrica, por uma questão interna de comunicação da empresa, e seja um tema mais afeito a um número limitado de técnicos e funcionários, e, por ser menos dependente da atitude geral dos funcionários e mais de tecnologia, acabe não sendo amplamente comunicado. Um dos fatores observados durante a pesquisa foi que as ações de controle e monitoramento da água estão direcionadas ao pessoal técnico de laboratório, 
que cuida do tratamento de água e gestão ambiental. Justifica-se, desta forma, a pouca correlação da assertiva. Esta observação, por um lado, reforça a importância atribuída por Sammalisto e Brorson (2008) aos aspectos de treinamento e comunicação, por outro, deixa aberta a hipótese de que os temas ambientais dentro da empresa podem ser afetados de maneira diferente dependendo do grau de tecnologia e de intervenção humana, de que dependem para um efetivo controle operacional. Há também a questão da forma de aplicação dos treinamentos de integração, misturados a outros temas, e que, portanto, podem estar sendo pouco absorvidos pelos funcionários, bem como treinamentos de conscientização realizados antes de auditoria ou quando do não alcance de objetivos e metas. Tais práticas não favorecem uma apreensão significativa de conteúdos, dada a aplicação uniforme de todo o assunto comunicado.

Nota-se, também, que assertivas mais genéricas de apelo mais "desenvolvimentista", tais como "A humanidade foi criada para governar o resto da natureza" e "Para manter um ambiente saudável teremos de controlar o crescimento econômico", não apresentaram correlação com nenhuma das práticas da empresa ou com a percepção de que alguma atitude dela influenciou o funcionário. A mudança de valores nas empresas é um dos elementos que Elkington (1997) traz como essencial para a sustentabilidade empresarial. Isso mostra que certos conceitos de sustentabilidade, por exemplo os valorizados por Sachs (1993) e Boff (2013), não necessariamente estão sendo aprofundados, podendo estar, de alguma forma, limitando os resultados da empresa.

Sobre a influência de condições e localização específica da empresa, vale ressaltar que a assertiva sobre poluição do ar revelou-se uma questão que não se correlacionou com nenhuma das assertivas sobre ações e práticas da organização. Isso pode ser pelo fato de que a empresa se localiza em um município que não está em área crítica de poluição do ar. Pergunta-se, nesse caso, se seria pertinente desenvolver escalas específicas para empresas ou localidades, de modo a refletir os principais problemas, ou se é possível ter uma escala de atitude ambiental que seja genérica. Isso pode ser tema para estudos futuros.

Chama a atenção o fato de que as assertivas "Aprendi na empresa a preocupar-me com o meio ambiente", "Sinto-me estimulado a uma atitude ambientalmente correta quando vejo a postura da diretoria da empresa e "Sinto-me estimulado a uma atitude ambientalmente correta quando vejo a postura dos líderes da empresa", confirmam a importância do papel exercido pela liderança, confirmando achados da literatura, por exemplo, em Kaur (2011) e Daily e Huang (2001). Conforme verificações em visitas, observou-se que os líderes existentes na empresa estudada são, em sua maioria, profissionais de perfil operacional que se destacaram de alguma forma nas suas atribuições e assumiram a responsabilidade sobre as atividades e um grupo de pessoas na empresa.

O modelo de liderança verificado, aparentemente, revela-se nessa empresa com potencial de influenciar uma gama maior de elementos da atitude dos funcionários, por apresentar o maior número de correlações com assertivas de atitude ambiental nos aspectos mais práticos e, de certo modo, informal. Essa liderança reflete-se possivelmente no fato de a empresa ser certificada ISO 14001 e de prezar por um funcionamento adequado e real de suas instalações e dos controles ambientais, conforme foi observado durante a visita. Isso possivelmente tenha relação ao que Yin e Schmeidler (2009) 
chamaram a atenção: o apoio da liderança e a inclusão das atividades ambientais no dia a dia dos funcionários são fatores essenciais para que os resultados dos sistemas de gestão ambiental apareçam.

Também o fato de a assertiva "Recebo constantemente na empresa a orientação sobre como não poluir o meio ambiente" estar correlacionada com várias assertivas relacionadas a atitude ambiental, reforça a importância do treinamento, que é um dos requisitos da norma ISO 14001 (ASSOCIAÇÃO..., 2004) e também destacado por autores como tendo um papel importante na gestão ambiental (DAILY; HUANG, 2001; JABBOUR; SANTOS, 2008; RENWICK; REDMAN; MAGUIRE, 2012).

Ao analisar as tabelas com os resultados das correlações, é possível imaginar que a "atitude ambiental do funcionário" possa ser separada em dois construtos: um mais relacionado ao discurso de questões práticas, como escolhas como consumidor, separação de resíduos e consumo de água e energia; outro relacionado às reais ações e práticas aplicadas pelos trabalhadores. Há uma indicação nos resultados de que esses temas têm resultados diferentes dos temas mais gerais, como questões sobre a capacidade de carga do planeta e o equilíbrio ecológico. Tendo isso em mente, a parte do questionário relativa às assertivas Q16, Q20, Q22, Q24, Q 26, Q28, Q34 e Q35 foi analisada quanto à confiabilidade, e o alfa de Cronbach resultou 0,614, ou seja, pouco acima do alfa geral do questionário. Embora visualmente haja correlação mais "densa" com essas questões, não há base suficiente para aprofundar esse tema.

\section{CONCLUSÕES}

A empresa estudada aplica os procedimentos e as ações em atendimento aos requisitos solicitados pela Norma ISO 14001, o que garante a certificação e a manutenção deste sistema por meio das evidências operacionais em registros nele existentes. Como itens de educação profissional, são realizados treinamentos de formação, instrução e conscientização para atendimento às necessidades de competência profissional solicitada pelo padrão normativo.

Algumas práticas ambientais da empresa e a percepção dessas práticas pelos colaboradores, apresentaram uma correlação de fraca a moderada em alguns temas, como a atitude ambiental dos funcionários fora do ambiente da empresa. Dentre os temas que se destacaram como tendo potencial de influenciar os funcionários, estão a liderança pelo exemplo e as práticas mais visíveis que, no caso da empresa estudada, se relacionam ao consumo de energia e à separação dos resíduos. Práticas existentes, mas que não são visíveis ao conjunto dos funcionários, como o reuso de água, acabam por não ter um potencial e influência tão grande.

Conclui-se, deste modo, que as ações de formação de desenvolvimento dos trabalhadores devem ser revistas no sentido de apresentar abordagens práticas à vida profissional e cotidiana e de forma a despertar no trabalhador a percepção ambiental referente à relação de seus impactos internos e externos sobre o meio ambiente. As percepções mais gerais sobre meio ambiente, embora marcadas como importantes para certos autores, não apresentaram correlação com as práticas domésticas dos funcionários. 
Para futuros estudos, recomenda-se a revisão da escala utilizada e o aprofundamento mediante o uso de técnicas de análise multivariada, tais como análise fatorial e modelagem por equações estruturais, com uma nova amostragem e, possivelmente, um questionário mais enxuto. Sugere-se o estudo do papel de mediação ou moderação de aspectos pessoais, tais como grau de instrução, função na empresa e idade, de forma a trabalhar treinamento e conscientização como foco em públicos específicos.

Outra recomendação seria analisar a temática com um questionário genérico aplicável a várias empresas, ou seja, replicar o mesmo questionário. Isso poderia ser feito utilizando-se ferramentas de análise multivariada mais avançadas.

\section{REFERÊNCIAS}

AGUIAR, A. O. Sistemas de gestão ambiental na indústria química: desempenho, avaliação e benefícios. 2004. Tese (Doutorado em Saúde Pública). Universidade de São Paulo, São Paulo, 2004.

ASSOCIAÇÃO BRASILEIRA DE NORMAS TÉCNICAS (ABNT). NBR ISO 14001. Sistema de Gestão Ambiental requisitos com orientação para uso. Rio de Janeiro: ABNT, 2004.

AYRE, C.; SCALLY, A. J. Critical values for Lawshe's content validity ratio: revisiting the original methods of calculation. Sage, p. 79-86, 2014.

AZEVEDO, C. E. F. et al. A estratégia de triangulação: objetivos, possibilidades, limitações e proximidades com o pragmatismo. ENCONTRO DE ENSINO E PESQUISA EM ADMINISTRAÇÃO E CONTABILIDADE - EnEPQ, 4., 2013. Brasília, 2013.

BOFF, L. Desenvolvimento ou sociedade sustentável? Correio Popular, 5 nov. 2013. Disponível em: <http:// correio.rac.com.br/_conteudo/2013/11/blogs/leonardo_boff/116956-desenvolvimento-ou-sociedade-sustentavel.html>. Acesso em: 3 out. 2017.

BOIRAL, O. Managing with ISO Systems. Long Range Planning, v. 44, p. 197-220, 2011.

BRASIL. Lei 6.938 - Política Nacional do Meio Ambiente. Brasília, ago. 1981.

CAMPOS, C. B.; POL, E. As crenças ambientais de trabalhadores provenientes de empresa certificada por SGA podem predizer comportamentos pró-ambientais fora da empresa? Estudos de Psicologia, v. 15, n. 2 p. 199-206, 2010.

COMISSÃO MUNDIAL SOBRE MEIO AMBIENTE. Relatório de Brubdtland - Nosso Futuro Comum. Brundtland: Organização das Nações Unidas, 1987.

DAILY, B. F.; HUANG, S.-C. Achieving sustainability through attention to human resource factors in environmental management. International Journal of Operations \& Production Management, p. 1.539-1.552, 2001.

DARNALL, N. Why Firms Mandate ISO 14001 Certification. Business \& Society, v. 45, n. 3, p. 1-28, 2006.

ELKINGTON, J. Canibais com garfo e faca. São Paulo: Makron, 1997. (Ed. brasileira).

FERREIRA, A. P. A. L. et al. Prática de sustentabilidade: um estudo bibliométrico com relação à percepção dos pesquisadores da área de Administração. Revista Metropolitana de Sustentabilidade, v. 5, n. 3 p. 4460, 2015.

FRANÇA, P. A. R.; GUIMARÃES, M. G. V.; ANDRADE, J. B. L. A educação ambiental no sistema de gestão integrado em uma empresa do polo industrial de Manaus (PIM). Revista de Estudos Ambientais, v. 17, n. 1, p. 27-42, 2015.

GOVINDARAJULU, N.; DAILY, B. F. Motivating employees. Industrial Management \& Data Systems, v. 104, p. 364-372, 2004.

HAIR JR., J. F. et al. Fundamentos de métodos de pesquisa em administração. Porto Alegre: Bookman, 2005.

2014.

A primer on partial lest squares structural equation modeling (PLS-SEM). Thousand Oaks: Sage,

HART, S. L. Beyond greening: strategies for a sustainable world. Harvard Business Review, v. 5, n. 1, p. 6576, 1997.

HERAS-SAIZARBITORIA, I.; BOIRAL, O. ISO 9001 e ISO 14001: Towards a research agenda on management system standards. International Journal of Management Reviews, v. 15, p. 47-65, 2013.

INTERNATIONAL ORGANIZATION FOR STANDARTIZATION (ISO). The ISO Survey 2014, 2015. Disponivel em: <http://www.iso.org/iso/iso-survey>. Acesso em: 16 jun. 2016. 
JABBOUR, C. C. Environmental training and environmental management maturity of Brazilian companies with ISO14001: empirical evidence. Journal of Cleaner Production, p. 1-8, 2013.

JABBOUR, C. C.; SANTOS, F. A. Relationships between human resource dimensions and environmental environmental. Journal of Cleaner Production, p. 51-58, 2008.

KAUR, H. Impact of human resource factors on perceived environmental performance: an empirical analusis of a sample of ISO 14001 EMS companies im Malaysia. Journal of Sustainable Development, p. 4, 2011.

LAWSHE, C. H. A quatitative approach to content. Personnel Psychology, p. 563-575, 1975.

LEFF, E. Saber ambiental: sustentabilidade, racionalidade, complexidade, poder. Petrópolis, RJ: Vozes, 2002.

LINK, S.; NAVEH, E. Standardization and discretion: does the environmental standard ISO 14001 lead to performance benefits? IEEE transactions on engineering management, v. 53, n. 4, p. 508-519, 2006.

MOLINA, S. M. G.; LUI, G. H.; SILVA, M. P. A ecologia humana como referencial teórico e metodológico para a gestão ambiental. OLAM Ciência e Tecnologia, p. 19-40, 2007.

OLIVEIRA, D. F.; MONTEIRO, L. V. G. Ecodesenvolvimento: uma abordagem sob o contributo de Ignacy Sachs. Revista de Direito, Economia e Desenvolvimento Sustentável, v. 1, p. 29-48, 2015.

PEDRINI, A. G.; PELLICCIONE, N. B. B. Educação Ambiental Empresarial no Brasil: uma análise exploratória sobre sua qualidade conceitual. Mundo \& Vida, v. 8, p. 1-9, 2007.

PELICIONI, A. F. Trajetória do movimento ambientalista. In: PHILIPPI JR., A.; ROMÉRO, M. A.; BRUNA, G. C. Curso de Gestão Ambiental. Barueri: Manole, 2007. Cap. 12. p. 431-457.

RENWICK, D. W.; REDMAN, T.; MAGUIRE, S. Green Human Resource Management: A Review and Research Agenda. International Journal of Management Reviews, p. 1-14, 2012.

RIBEIRO NETO, J. M.; TAVARES, J. C.; HOFFMAN, S. C. Sistemas de gestão integrados. São Paulo: Senac, 2008.

SACHS, I. Estratégias de transição para o século XXI. In: BURSZTYN, M. Para pensar o desenvolvimento sustentável. 2. ed. São Paulo: Brasiliense, 1993.

SAMMALISTO, K.; BRORSON, T. Training and communication in the implementation of environmental management systems (ISO 14001): a case study at the University of Gävle, Sweden. Journal of Cleaner Production, v. 16, p. 299-309, 2008.

SARKIS, Joseph et al. Evaluating environmentally conscious business practices. European journal of operational research, v. 107, n. 1, p. 159-174, 1998.

SHRIVASTAVA, P. The Role of Corporations in Achieving Ecological Sustainability. Academy of Management, p. 936-960, 1995.

TUAN, Y.-F. Topofilia: um estudo da percepção, atitudes e valores do meio ambiente. Trad. Lívia Oliveira. Londrina: Eduel, 2012.

VALLE, C. E. Qualidade Ambiental ISO14000. 12. ed. São Paulo: Senac, 2012.

VERGARA, S. C. Métodos de pesquisa em administração. 2. ed. São Paulo: Atlas, 2006.

WHITMARSH, L. Behavioural responses to climate change: asymmetry of intentions and impacts. Journal of Environmental Psychology, p. 13-23, 2009.

YIN, H.; SCHMEIDLER, P. J. Why Do Standardized ISO 14001 Environmental Management Systems Lead to Heterogeneous Environmental Outcomes? Business Strategy and the Environment, v. 18, p. 469-486, 2009.

YIN, R. K. Estudo de caso: planejamento e métodos. 3. ed. Porto Alegre: Bookman, 2005. 